\title{
Effect of Whole Body Vibration versus Suspension Therapy on Balance and Functional Capacity in Children with Diplegic Cerebral Palsy
}

\author{
Rasha A. Mohamed ${ }^{1 *}$, Abd El Aziz A. Sherief ${ }^{2}$, El Sayed H. Mohamed ${ }^{3}$ \\ ${ }^{1}$ Assistant professor in the department of Physical Therapy for Growth and \\ Developmental Disorders in Children and its Surgery, Faculty of Physical Therapy, \\ Cairo University, Egypt. \\ ${ }^{2}$ Assistant professor in the department of Physical Therapy for Growth and \\ Developmental Disorders in Children and its Surgery, Faculty of Physical Therapy, \\ Kafer El Sheikh University, Egypt. \\ ${ }^{3} \mathrm{PHD}$ in Physical Therapy for cardiopulmonary disorders, Physical Therapy \\ Department, Buraydah Private Colleges, Saudi Arabia.
}

${ }^{*}$ Corresponding author: Rasha A. Mohamed

E-mail address: dr.rashapt@gmail.com

\begin{abstract}
Objectives: To compare the effects of whole body vibration with suspension therapy in relation to balance and functional capacity in diplegic cerebral palsied children. Subjects and methods: Thirty diplegic cerebral palsied children of both sexes were enrolled in the study with their ages ranged between 7 and 9 years. They were randomly and equally distributed into two study groups. The first group underwent the whole body vibration training and second group underwent suspension therapy through the spider cage. Also, both groups received the same designed physical therapy program. Stability indices and functional capacity were evaluated by using 6-minute walk test and Biodex stability system respectively before and after six successive months of treatment. Results: significant differences were obtained when comparing the pre and post treatment results of all measuring variables of both groups showed $(P<0.05)$ except non-significant differences in medio-lateral stability index $(P>0.05)$ in group I. Also, the results showed that the group underwent the suspension had more effect in comparison to the group of whole body vibration. Conclusion: Whole body vibration and suspension therapy training are effective additional tools in rehabilitation of diplegic cerebral palsied children with decreased balance and functional capacity in favor of the suspension therapy.
\end{abstract}

Key words : Whole body vibration; suspension therapy; Balance; Functional capacity; Diplegic Cerebral Palsy.

Rasha A. Mohamed et al /International Journal of PharmTech Research, 2019,12(1): 80-89.

DOI: http://dx.doi.org/10.20902/IJPTR.2019.120111 


\section{Introduction}

Cerebral palsy could be defined as a group of sensorimotor disorders caused by a non-progressive lesion during development of the brain resulting in disorders of posture and movement [1]. Diplegic CP considers the most common type of CP in which the lower limbs are more affected than upper limbs [2]. Frequent falls, impaired balance and gait disturbances are common disorders in CP children [3]. Decreased range of movement, muscle strength, sensory organization, motor coordination, cognition and abnormal muscle tone [4], abnormalities in the vestibular apparatus [5] causes the balance disorders in CP children. In diplegic $\mathrm{CP}$ children, balance is mainly affected due to impairments of neural motor control mechanisms and musculoskeletal disorders [6]. Most of the therapy program aim to keep the alignment of the extremities to overcome the edema, soft tissue overstretch and pain through the weight-bearing exercises [7].Whole-body vibration (WBV) is one of the methods of muscle strengthening $[\mathbf{8 , 9}$ ]. A study showed that WBV therapy was superior to a low intensity resistance training program in improving isometric and dynamic muscle strength in middle aged and older women [10]. The patient is practicing on vibrating platform either in a standing or moving positions. Controlling of balance is necessary for performing most of functional activities which helps the children to maintain their balance during unexpected disturbances when they make a movement toward the border of the limit of stability [11]. The children keep their feet in contact with the moving surface of WBV more time than walking over ground [12]. Researchers are needed to investigate the longer effects of WBV on the child's capability to keep their balance while overcoming the obstacles [13]. Suspension therapy is an efficient method in the treatment of CP children. It could be used with traditional physical therapy methods to improve balance with increasing independence which improves the muscle strength, function of the vestibular system coordination and balance [14]. Biodex Stability System (BSS) enables objective assessment of balance [15]. Six minute walk test (6MWT) is used to determine the functional ability [16], in which the subjects walk as they can in 6 minutes (min.) about a pre-measured distance. The 6MWT is an effective for assessing the children with musculoskeletal disorders as walking [17]. This test is an indirect assessment of subject's capacity during activities of daily living and follow-up of the treatment [18] and to measure walking ability [19]. The test has been validated in several populations, including patients CP [20].

Several studies were conducted to investigate the effects of WBV and suspension therapy in CP children. So, this study was designed to compare between the effects of WBV with suspension therapy in relation to balance and functional capacity in diplegic $\mathrm{CP}$ children.

\section{Materials and Methods}

Thirty children with diplegic $\mathrm{CP}$ from both genders, with their ages ranged between 7 and 9 years, were enrolled in this study via National Institute for Neuro-Motor System and Out-patient Clinic of Faculty of Physical Therapy, Cairo University. Selecting this age group could be attributed to the fact that, agility and balance defects are common in CP children in the age from 7 to 14 years [21]. Children with 7 to 10 years of age are capable of maintaining balance and effectively use the vestibular system as in adult [22].

The inclusion criteria were as following: children had sufficient cognition, the degree of spasticity was $1^{+}$to 2 according to Modified Ashowrth Scale [23]; having level II on Gross Motor Functional Classification Scale (GMFCS) [24].They had mild to moderate dynamic deformity. All the subjects were using AFOs on regular basis. They were able to walk independently at least 10 meters without the use of walking aids but with crouch gait. The strength of quadriceps, hamstring and calf muscles is at least grade 3 according to Kendall et al. [25].

The exclusion criteria were as following: hearing or vision loss, lower limb surgery or Botulinum toxin injections of the lower limb within the last 6 months, cardiac anomalies, mixed CP type.

The children were randomly and equally distributed into two study groups. Study group I included 15 children ( 8 girls and 7 boys) received WBV training and study group II included 15 children ( 7 girls and 8 boys) received suspension therapy. In addition, both groups received the same designed exercise program.

This work met the Ethics of the World Medical Association (Declaration of Helsinki) for studies of the humans. The Parents signed a consent form before participation. Purpose of the study, potential risks, benefits and the procedures involved for evaluation and treatment were explained to all parents. 


\section{Randomization}

Forty children were selected for eligibility. Ten children were excluded because nine of them did not meet the inclusion criteria and the parent of the tenth child refused to participate in the study. Randomization process was performed following the baseline measurements by closed envelopes. The 30 closed envelopes were prepared by the authors. Each envelope contained a labeled card with either study group I or study group II. Finally, each child was instructed to draw his/ her envelope which contained whether he/she was allocated to the study group I or II. The flow chart of the study design is represented in Figure 1.
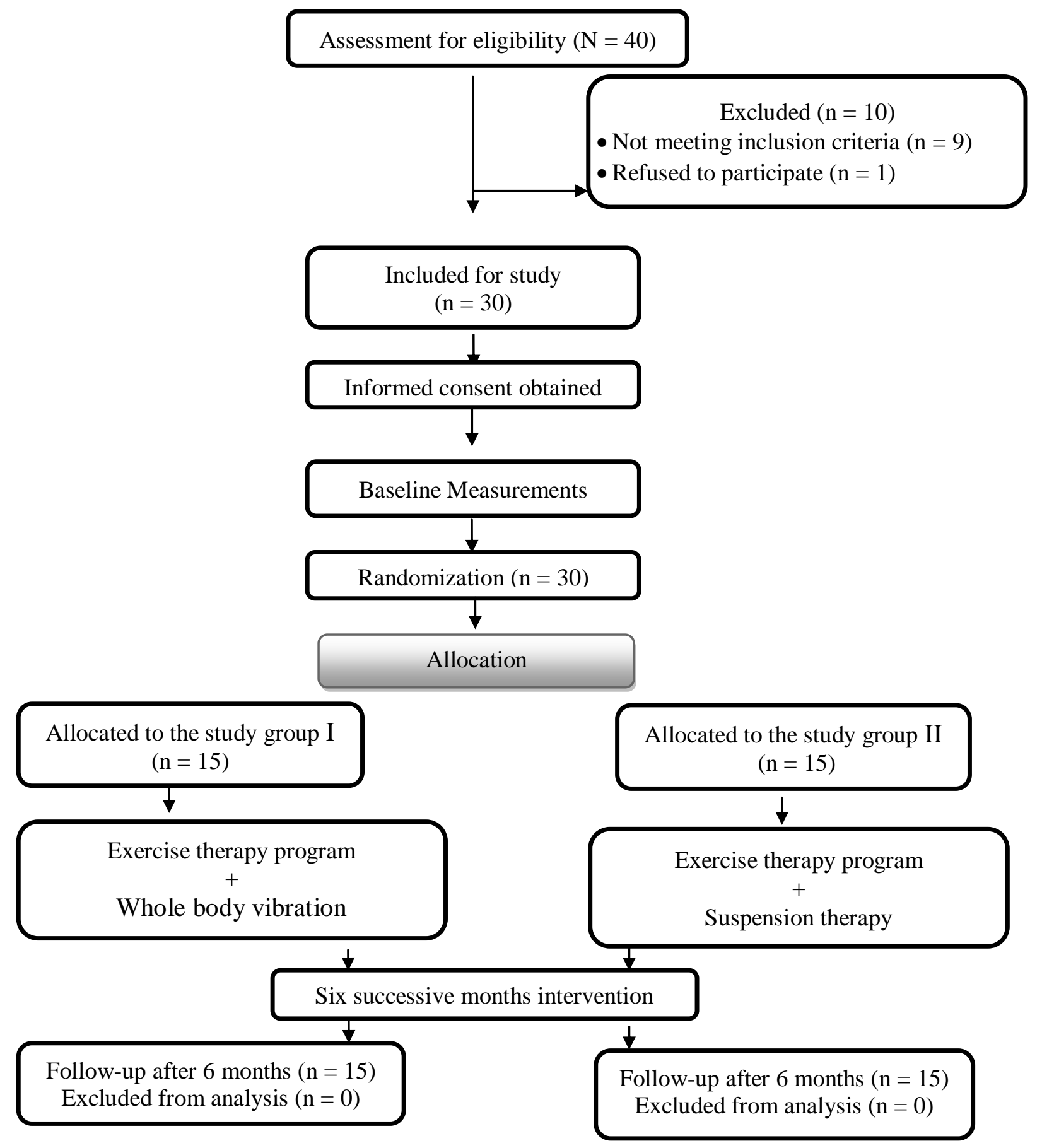

Figure 1. Flow chart showing the experimental design of the study 


\section{Evaluation}

\section{a- Preliminary evaluation}

The motor functions of the children were measured by the Gross Motor Function Measure (GMFM-88) [26]. The GMFM-88 was designed to measure changes in GMF over time in children with motor disorders as children with CP [27]. It includes 5 dimensions (lying and rolling; sitting; crawling and kneeling; standing; walking, running, and jumping) [28]. The percentage of the maximum score for each dimension is taken.

\section{b. Balance evaluation and Six Minute Walk Test}

A familiarity session was conducted before each test to to ensure the comfort of the children with the research team and to be familiar with different test steps.

\section{Balance evaluation}

The BSS included a support handle and an anterior screen adjusted according to the child's height. The screen provided feedback through it the child could keep the cursor in the center to get the best score of balance. Dynamic limit of stability on stability level 8 was performed. Moreover, level 8 represented the most stable level, as high test-retest reliability for the BSS was reported when using high resistance levels [29]. When the child was centered on the platform, heels coordinates and feet angles and introduced to the system. After the platform changed to an unstable position, the child focused on the visual feedback from the screen which placed in front of him/her while trying to maintain the cursor in the middle of the screen. The test consumed 30 seconds (sec.). At the end of each test, the result was obtained on the screen consisting of overall stability index (Overall SI), antero-posterior stability index (A/P SI) and medio-lateral stability index (M/L SI). The test was repeated for 3 times and the mean of the 3 trials was taken. The higher mean values indicated balance difficulty [30].

\section{Six Minute Walk Test}

According to the guidelines of the American Thoracic Society, the children in both groups instructed to walk on a rectangular and unobstructed pathway which was conducted by the authors. The walking distance was 20 meters $(\mathrm{m})$ between turning points. The therapist followed closely with a stopwatch to measure the distance covered by the child in $6 \mathrm{~min}$. and to ensure safety. The child was encouraged to cover as many laps of as he/ she could in 6 min. without running [31].

\section{Treatment protocol}

Each treatment was given for 1 hour $/ 3$ days/ week for six successive months. Each group received the same exercises program for $30 \mathrm{~min} / 3$ days/ week for six successive months. In addition, the children in the study group I underwent WBV and study group II underwent suspension therapy for $30 \mathrm{~min} / 3$ days/ week for six successive months. A familiarity session was conducted before the treatment protocol to all the children in which the children practiced WBV and suspension therapy.

\section{Whole body vibration}

The WBV device (Vibraflex Home Edition II®, Orthometrix Inc, and White Plains, NY) was used. The treatment schedule was adopted from previous studies $[32,33,34]$. Each session included cycles of 3 min of vibration followed by 3 min rest till the end of the session. So, the duration of each treatment session was about $9 \mathrm{~min}$. The child stood on the vibration plate. The peak-to-peak displacement increased with increasing the distance between the feet and the center of the plate. Three places were represented on the plate labeled as 1,2 and 3 indicating the peak to-peak displacements of 2, 4 and $6 \mathrm{~mm}$ respectively. The tilt angle was firstly 35 degrees which was increased gradually till the device placed completely on the ground that was depended on the ability of the child to keep the upright position. The children were firstly connected to the tilting table through two straps (the first one was at the knees and the second one at the pelvis level). The frequency of 12 $\mathrm{Hz}$ with $2 \mathrm{~mm}$ displacements was firstly used. The child was instructed to flex his/ her knees and hips between 10 to 45 degrees in order to prevent reaching of the vibration to the head. The child was encouraged to correct his/ her posture through visual feedback from the mirror of the WBV device and verbal cueing of the therapist. 


\section{Suspension therapy via spider cage}

The child was standing in the medial of the spider cage while he/ she was hooked up by a belt around his/her waist by velcro straps. The belt was connected to the cage by elastic cords in a spider shape. The suspension provided assistance, support or resistance during training [35]. A group of exercises were applied as following:

1. Cords beside: when the cords connected to the belt at the same level of connection of the cords to the cage, there was full weight bearing on both lower limbs. The cords were elastic to help the child to control and re-adjust him/ herself. In the beginning, the cords' tensions were equal to enable the child to assume the upright posture and gradually decreased. Whereas, the tension of the front and back cords was interchangeably decreased while repeating the same exercises. A group of exercises balance were applied to improve which included: kneeling, half kneeling, kneel-walking, standing weight shift, stoop and recover, squatting from standing position, throwing ball, kicking ball, standing on one foot standing on balance board, stepping, jumping in place and jumping abroad.

2. Full suspension: the child was fully suspended when level of connection of the cords to the cage was higher than its connection to the belt. The vestibular stimulation could be provided. The therapist pulled the child backward to swing him/her forward and backward, side to side and up and down movements through space until he/ she stopped. Each exercise was performed for 1-2 min followed with 1-2 min rest [36].

In addition, each child in both groups underwent individually the same designed exercises program. The program was included the following:

- Stretching exercises for the tight muscles

- Strengthening exercises for the antispastic muscles

- Balancing exercises in standing

- Gait training

\section{Data analysis}

The data of stability indices and the functional capacity of both groups were analyzed. The mean ( $\overline{\mathrm{X}})$ and standard deviation (SD) of the measuring variables in addition to the age, weight and height were done. Paired t-test was conducted to compare the pre and post treatment results in each group. Unpaired t-test was conducted to compare pre and post treatment results of both groups. The significance level for the statistical tests was $\mathrm{p}<0.05$. The statistical analysis was done by SPSS (Statistical Package for Social Sciences, version 20).

\section{Results}

\section{Subjects' characteristics}

Table 1, presented the age, weight and height of both study groups. The obtained results showed nonsignificant differences between both groups indicating homogeneity of the study sample for both groups $(P>$ $0.05)$.

Table 1. Subjects' characteristics

\begin{tabular}{lcccc}
\hline & Group I (n=15) & Group II $(\mathbf{n}=\mathbf{1 5})$ & $\boldsymbol{t}$-value & $\boldsymbol{p}$-value \\
\hline Age (years) & $7.11 \pm 0.56$ & $7.52 \pm 0.63$ & 1.88 & 0.07 \\
Weight (Kg) & $27.06 \pm 3.79$ & $27.86 \pm 4.43$ & 0.53 & 0.59 \\
Height (cm) & $115.12 \pm 4.59$ & $117.33 \pm 6.85$ & 1.04 & 0.32 \\
\hline
\end{tabular}

Data are expressed as $\overline{\mathrm{X}} \pm \mathrm{SD} \quad \mathbf{k g}$ : Kilogram $\quad \mathbf{c m}$ : Centimeter $\boldsymbol{P}$-value: level of significance 


\section{Stability indices}

Table 2, presented the stability indices of both groups. The Unpaired t-test revealed non-significant differences between both groups in the pre-treatment results $(P>0.05)$ and significant differences of post treatment results with higher results to group $\operatorname{II}(P<0.05)$. The Paired t-test of both groups recorded significant differences between pre and post-treatment results $(P<0.05)$ which were in the form of significant reduction in all stability indices of both groups except non-significant differences in $\mathrm{M} / \mathrm{L}$ SI $(P>0.05)$ in group I was recorded.

Table 2. Stability indices of both groups

\begin{tabular}{l|cccccc}
\hline \multicolumn{1}{c}{} & \multicolumn{3}{c}{ Group I } & & \multicolumn{3}{c}{ Group II } \\
\cline { 2 - 7 } & Overall SI & A/P SI & M/L SI & Overall SI & A/P SI & M/L SI \\
\hline Pre & $1.91 \pm 0.23$ & $1.58 \pm 0.29$ & $1.67 \pm 0.28$ & $1.89 \pm 0.25$ & $1.53 \pm 0.24$ & $1.60 \pm 0.21$ \\
Post & $1.64 \pm 0.26$ & $1.38 \pm 0.20$ & $1.60 \pm 0.25$ & $1.37 \pm 0.18$ & $1.25 \pm 0.17$ & $1.20 \pm 0.15$ \\
$\boldsymbol{t}$-value & -3.012 & -2.199 & -0.722 & -6.538 & -3.687 & -6.003 \\
$\boldsymbol{p}$-value & $0.0054^{*}$ & $0.0363^{*}$ & 0.4761 & $0.0001^{*}$ & $0.0010^{*}$ & $0.0001^{*}$ \\
\hline
\end{tabular}

Data are expressed as $\overline{\mathrm{X}} \pm \mathrm{SD} \quad$ SI: Stability index $\quad \mathbf{A} / \mathbf{P}$ : Antero- posterior

M/L: Medio-lateral $\quad \boldsymbol{P}$-value: Level of significance $\quad *$ Significant at $P<0.05$

\section{Six- minute walk test}

Table 3, presented the 6MWT of both groups. The Unpaired t-test revealed non-significant differences between both groups in the pre-treatment results $(P>0.05)$ and significant differences of post treatment results with higher results to group $\mathrm{II}(P<0.05)$. The Paired t-test of both groups recorded significant differences between pre and post-treatment results $(P<0.05)$.

Table 3: Six minute walk test of both groups

\begin{tabular}{lcc}
\hline & Group I (meter) & Group II (meter) \\
\hline Pre & $298 \pm 8.34$ & $295.57 \pm 9.30$ \\
Post & $330 \pm 7.45$ & $350.32 \pm 10.75$ \\
$\boldsymbol{t}$-test & 11.08 & 14.92 \\
$\boldsymbol{p}$-value & $0.0001^{*}$ & $0.0001^{*}$ \\
\hline
\end{tabular}

Data are expressed as $\overline{\mathrm{X}} \pm \mathrm{SD} \quad P$-value: level of significance $*$ Significant at $P<0.05$

\section{Discussion}

Improvement of mobility in $\mathrm{CP}$ children could effectively result in savings of health care system [37]. Balance and gait disorders are the most problems of CP [38]. The clinical implication of this study was to the present study was designed to compare the effects of WBV training with suspension therapy in relation to balance and functional capacity in diplegic CP children. Both methods are effective additional tools to the rehabilitation program in favor of the suspension therapy with high recommendation for using suspension therapy.

The Paired t-test of both groups recorded significant differences between pre and post-treatment results $(P<0.05)$ which were in the form of significant reduction in all stability indices and 6MWT of both groups except non-significant differences in M/L SI $(P>0.05)$ in group I was recorded. This improvement might be attributed to the combined effect of a designed exercise program and sensory stimulation through WBV or 
suspension therapy which worked at a multi-system level: the visual, proprioceptive, and vestibular inputs leading to muscle tone modulation that encouraged the appearance of normal motor response, improved the sensorimotor integrative process and enhanced the relationship between the sensory and motor system [39].

The improvement in the stability indices of the study group received suspension therapy could be explained by Stillman [40] who stated that during the learning process of skills, proprioceptive awareness of movements and postures and is necessary. The proprioceptive system could detect and adjust the slower movements. Also, it could be able to stimulate precise, immediate and fast reflexive compensatory reactions in response to sudden changes in internal or external forces during standing balance. Keen [41] reported that the spider cage could help the patient to overcome the effect of gravity in static and dynamic patterns and modulate the muscle tone to keep the body from falling. McCollum and Leen [42] added that spider cage could provide the child with more support to decrease the center of pressure (COP) displacement and keeping the COP near the center. So, suspension therapy is an effective tool added to traditional physical therapy treatment to improve the postural stability in children with CP [43].

The functional capacity of the children in both groups was improved which could be related to improvement in the balance through improving the biomechanical loading on lower limbs. These results are supported by the American Thoracic Society which mentioned that one of the factors which might contribute to increasing of functional capacity is improved biomechanical loading of the joints which leads to a more efficient and comfortable gait. Also, improved body image, increased confidence, and decreased fear of movement could result in improvement in functional walking [44].

Unpaired t-test revealed significant differences of post treatment results of both groups with higher results to group received the suspension therapy $(P<0.05)$. These results could be attributed to the improvement of the function of vestibular system and proprioceptive system. The spider cage might stimulate the otolith organs of the vestibular through the linear displacement of the cage. These results in consistent with Senior [45] who stated that the suspension therapy could develop the equilibrium reaction to maintain and regain standing balance through vestibular input, proprioception and vision.

The study has some limitations including, only one kind of CP with relatively small sample size which limit the generalizability of the findings. Second, the short duration of the study to detect whether the effects of the suspension therapy or WBV were maintained and whether there were any longer term outcomes after terminating the program. Therefore, future studies can extend the duration of the study to help determine the long term sustainability of the program with a large sample sizes and other types of $\mathrm{CP}$.

\section{Conclusion}

According to the results of this study, its conclusion that, the WBV and suspension therapy are effective additional tools to the rehabilitation program for children with spastic diplegic $\mathrm{CP}$ in improving the balance and functional capacity with high recommendation for using suspension therapy.

\section{Acknowledgments}

The authors thank all parents and their children for their collaboration, cooperation and confidence. The authors declare no conflict of interest was present. The present study was conducted through the personal fund of the authors. 


\section{References}

1. Rosenbaum P, Paneth N, Leviton A, Goldstein H, Bax M, Damiano D, et al.. A report: The definition and classification of cerebral palsy, Developmental Medicine \& Child Neurology, 2006, 49: 8-14.

2. Bjornson K, Hays R, Graubert C, Price R, Won F, McLaughlin JF, et al. Botulinum toxin for spasticity in children with cerebral palsy: a comprehensive evaluation. Pediatrics, 2007, 120: 49-58. doi:10.1542/peds.2007-0016.

3. Harvey A, Robin J, Morris ME, Graham HK, Baker R.A systematic review of measures of activity limitation for children with cerebral palsy, Developmental Medicine \& Child Neurology, 2008, 50:190 198. doi:10.1111/j.1469-8749.2008.02027.x.

4. De Oliveira CB, de Medeiros IR, Frota NA, Greters ME, Conforto AB. Balance control in hemiparetic stroke patients: main tools for evaluation, Journal of Rehabilitation Research \& Development, 2008, 45(8):1215-1226. doi:10.1682/JRRD.2007.09.0150.

5. Inagaki T, Morita M, Cureoglu S, Schachern PA, Nomiya S, Nomiya R, Paparella MM. Peripheral vestibular system in Down syndrome: quantitative assessment of vestibular histo-pathology. Otolaryngology-Head and Neck Surgery, 2011, 144(2):280-283. doi:10.1177/0194599810391204.

6. Peng YC, Lu TW, Wang TH, Chen YL, Liao HF, Lin KH, et al. Immediate effects of therapeutic music on loaded sit-to-stand movement in children with diplegia. Gait Posture, 2011, 33: 274-278. doi:10.1016/j.gaitpost.2010.11.020.

7. Jaraczewska E, Long C. Kinesio taping in stroke: improving functional use of the upper extremity in hemiplegia, Topics in Stroke Rehabilitation,., 2006, 13 (3): 31-42. doi:10.1310/33KA-XYE3-QWJBWGT6.

8. Prisby RD, Lafage-Proust MH, Malaval L, Belli A, Vico L.Effects of whole body vibration on the skeleton and other organ systems in man and animal models: what we know and what we need to know. Ageing Research Reviews, 2008, 7:319-329. doi:10.1016/j.arr.2008.07.004.

9. Rittweger J. Vibration as an exercise modality: how it may work, and what its potential might be. European Journal of Applied Physiology, 2010 Mar;108(5):877-904. doi:10.1007/s00421-009-1303-3.

10. Verschueren SM, Roelants M, Delecluse C, Swinnen S, Dirk Vanderschueren D, Boonen S.Effect of 6month whole body vibration training on hip density, muscle strength, and postural control in postmenopausal women: a randomized controlled pilot study. Journal of Bone and Mineral Research, 2004, 19:352-359. doi:10.1359/JBMR.0301245.

11. Woollacott MH, Shumway-Cook A. Postural dysfunction during standing and walking in children with CP: What are the underlying problems and what new therapies might improve balance?, Neural Plasticity, 2005, 12: 2-3. doi:10.1155/NP.2005.211.

12. Matsuno VM, Camargo MR, Palma GC,Alveno D, Barela AM. Analysis of partial body weight support during whole body vibration and over ground walking of children with CP. Rev Bras Fisider, 2010, 14(5).

13. Fowler EG, Kolobe TH, Damiano DL, Thorpe DE, Morgan DW, Brunstrom JE, Coster WJ, Henderson RC, Pitetti KH, Rimmer JH, Rose J, Stevenson RD.Promotion of physical fitness and prevention of secondary conditions for children with cerebral palsy: section on pediatrics research summit proceedings, Physical Therarpy, 2007, 87:1495-1510. doi:10.2522/ptj.20060116.

14. Levinson GM. Institute's intensive therapy programs provide alternative treatment for individuals with cerebral palsy and brain trauma, Journal of Except Parent (EP), 2003, 12:42-47.

15. Perron M, Hebert LJ, McFadyen BJ, Belzile S, Regniere M .The ability of the Biodex Stability System to distinguish level of function in subjects with a second-degree ankle sprain, Clinical Rehabilitation, 2007, 21: 73-81. doi:10.1177/0269215506071288.

16. Burr JF, Bredin SS, Faktor MD, Warburton DE. The 6-minute walk test as a predictor of objectively measured aerobic fitness in healthy working-aged adults, Physician and Sports Medicine, 2011, 39(2):133-139. doi:10.3810/psm.2011.05.1904.

17. Hassan J, vander Net J, Helders PJ, Prakken BJ, Takken T.6 min walk test in children with chronic conditions, British Journal of Sports Medicine, 2010, 44(4):270-274. doi:10.1136/bjsm.2008.048512.

18. Enright PL. The six-minute walk test, Respiratory Care, 2003, 48(8):783-785.

19. Whaley MH, Brubaker PH, Otto RM, Armstrong LE, et al. ACSM's guidelines for exercise testing and prescription. $7^{\text {th }}$ ed.Lippincott Williams and Wilkins, 2006. 
20. Vis JC, Thoonsen H, Duffels MG, et al. Six-minute walk test in patients with Down syndrome: validity and reproducibility, Archives of Physical Medicine and Rehabilitation, 2009;,90 (8): 1423-1427. doi:10.1016/j.apmr.2009.02.015.

21. Henderson SE, Morris J, Frith U. The motor deficit in Down syndrome children: A problem of Aiming, Journal of Child Psychology and Psychiatry, 1981, 22:233-244. doi:10.1111/j.14697610.1981.tb00549.x.

22. Westcott SL, Lowes LP, Richardson PK. Evaluation of postural stability in children: current theories and assessment tools, Physical Therapy, 1997, 77(6):629-645. doi:10.1093/ptj/77.6.629.

23. Bohannon RW, Smith MB.Inter-rater reliability of a modified Ashworth scale of muscle spasticity, Physical Therapy, 1987, 67(2):206-208. doi:10.1093/ptj/67.2.206.

24. Palisano R, Rosenbaum P, Walter S, Russell D, Wood E, Galuppi B. Development and reliability of a system to classify gross motor function in children with cerebral palsy, Developmental Medicine and Child Neurology, 1997, 39: 214-223. doi:10.1111/j.1469-8749.1997.tb07414.x.

25. Kendall FP, McCreary EK, Provance PG, Rodgers MM, Romani WA. Muscles: testing and function with posture and pain. $5^{\text {th }}$ ed. Lippincott: Williams and Wilkins, 2005: 49.

26. Russell DJ, Rosenbaum PL, Wright M, Avery LM. Gross Motor Function Measure (GMFM-66 and GMFM-88) User's Manual. Clinics in Developmental Medicine. London, UK: Mac Keith Press, 2002.

27. Nolan KW, Cole LL, Liptak GS.Use of Botulinum Toxin Type A in Children With Cerebral Palsy, Physical Therapy, 2006, 86 (4): 573- 584

28. Russell DJ, Rosenbaum PL, Gowland C, et al. Manual for the Gross Motor Function Measure. $2^{\text {nd }}$ ed. 1993. (Available from CanChild Centre for Childhood Disability Research, Room 408, Institute for Applied Health Sciences, McMaster University, Ontario, Canada.

29. Cachupe W, Shifflett B, Kahanov L, Wughalter EH. Reliability of Biodex Balance System Measures, Measurements in Physical Education and Exercise Science, 2001, 5(2): 97-108. doi:10.1207/S15327841MPEE0502_3.

30. Pereira HM, de Campos TF, Santos MB, Cardoso JR, Garcia Mde C, Cohen M. Influence of knee position on the postural stability index registered by the Biodex Stability System. Gait Posture 2008, 28(4): 668-672. doi:10.1016/j.gaitpost.2008.05.003.

31. ATS statements: guidelines for the six-minute walk test. American Journal of Respiriratory Critical Care Med 2002; 166:111-7? Available at https://www.thoracic.org/statements/resources/pfet/sixminute, doi:10.1164/ajrccm.166.1.at1102.

32. Semler O, Fricke O, Vezyroglou K, Stark C, Schoenau E. Preliminary results on the mobility after whole body vibration in immobilized children and adolescents, Journal of Musculoskeletal Neuronal Interactions, 2007, 7:77-81.

33. Semler O, Fricke O, Vezyroglou K,Stark C, Stabrey A, Schoenau E.Results of a prospective pilot trial on mobility after whole body vibration in children and adolescents with osteogenesis imperfect, Clinical Rehabilitation, 2008, 22: 387-394. doi:10.1177/0269215507080763.

34. Rauch F. Vibration therapy, Developmental Medicine and Child Neurology, 2009, 51 (4): 166-168. doi:10.1111/j.1469-8749.2009.03418.x.

35. Koscielny I, Koscielny R. Suit performs physical therapy: space like device helps ease movement with cerebral palsy. http:// www.sunbeamtherapy.com/therasuit.html, 2002.

36. Kelly G. Vestibular stimulation as a form of therapy. Physiotherapy, 1989, 75(3):136-140. doi:10.1016/S0031-9406(10)62765-4.

37. Damiano DL. Activity, activity, activity: rethinking our physical therapy approach to cerebral palsy, Physical Therapy, 2006, 86:1534-1540. doi:10.2522/ptj.20050397.

38. Henderson RC, Lark RK, Newman JE, Kecskemthy H, Fung EB, Renner JB, Harcke HT. Pediatric reference data for dual X-ray absorptiometric measures of normal bone density in the distal femur, American Journal of Roentgenology, 2002, 178:439-443. doi:10.2214/ajr.178.2.1780439.

39. Carvalho RL, Almeida GL. The effect of vibration on postural response of Down syndrome individual on the seesaw, Research in Developmental Disabilities, 2009, 30(6):1124-1131. doi:10.1016/j.ridd.2009.02.012.

40. Stillman BC. Making sense of proprioception: the meaning of proprioception: Kinesthesia and related terms. Physiotherapy, 2002, 88(11):667-676. doi:10.1016/S0031-9406(05)60109-5.

41. Keen PA. Well-suited for therapy device helps children with cerebral palsy gain motor skills, Current Newspaper Art, 2003, 11: 16-20. 
42. McCollum G, Leen T. The form and exploration of mechanical stability limits in erect stance. In: Cook AS, Woollacott MJ, editors. Motor control theory and practical applications. Philadelphia: Lippinocott; 2007, p. 197.

43. Olama KA, Thabit NS. Effect of vibration versus suspension therapy on balance in children with hemiparetic cerebral palsy,Egyptian Journal of Medical Human Genetics, 2012, 13:219-226. doi:10.1016/j.ejmhg.2011.11.001.

44. Zaky LA, Hassan WF. Effect of partial weight bearing program on functional ability and quadriceps muscle performance in hemophilic knee arthritis. Egyptian Journal of Medical Human Genetics, 2013, 14(4):413-418. doi:10.1016/j.ejmhg.2013.02.002.

45. Senior R. Cage-fighters children use a 'Spider Cage' to combat neurological conditions, Advance for Physical Therapy and Rehab Medicine, 2007, 18(25):32-34. 